\title{
Patient Perceptions of Surgeon Reimbursement for Rotator Cuff Repair
}

\author{
Brendan R. Southam, ${ }^{* \dagger} \mathrm{MD}$, Zachary Crawford, ${ }^{\dagger}$ PharmD, and Brian M. Grawe, ${ }^{\dagger} \mathrm{MD}$ \\ Investigation performed at the Department of Orthopaedic Surgery, \\ University of Cincinnati Medical Center, Cincinnati, Ohio, USA
}

Background: Previous studies in the arthroplasty, spine, and shoulder and elbow literature have shown that patients perceive Medicare reimbursement to surgeons to be much higher than current reimbursement schedules.

Purpose: To evaluate patient perceptions of surgeon reimbursement for various rotator cuff repair (RCR) procedures.

Study Design: Cross-sectional study.

Methods: We surveyed 153 patients who presented to a single surgeon's orthopaedic sports medicine clinic between October 2016 and March 2017. Patients with a new complaint of hip or knee pain, those with a new complaint of shoulder pain, or those who had undergone shoulder surgery 1 year or more prior to their current visit were included. Patients were asked how much they thought surgeons should be reimbursed for RCR procedures, including arthroscopic repair of a simple tear and a massive tear as well as open repair of an acute tear and a chronic tear. They were also asked to estimate how much they thought surgeons were reimbursed by Medicare for these procedures. They were then given actual Medicare reimbursement rates for these procedures and asked whether they believed surgeons should be reimbursed that amount.

Results: For arthroscopic repair of a rotator cuff tear, patients believed that surgeons should receive a mean ( \pm SEM) reimbursement of US $\$ 5645 \pm \$ 442$. This was significantly more than their estimate of what surgeons were actually reimbursed by Medicare ( $\$ 3644 \pm$ $\$ 408 ; P=.001)$. Patients also believed that surgeons should be reimbursed more than their estimate of what surgeons were actually reimbursed for arthroscopic repair of a massive tear $(\$ 8066 \pm \$ 708$ vs $\$ 4694 \pm \$ 476 ; P=.0001)$, open repair of an acute tear $(\$ 8428 \pm$ $\$ 768$ vs $\$ 4549 \pm \$ 396 ; P=.00001)$, and open repair of a chronic tear ( $\$ 8902 \pm \$ 844$ vs $\$ 4639 \pm \$ 438 ; P=.00001)$. Both types of patient perceptions were higher than the actual state Medicare reimbursement data for all procedures surveyed $(P<.001)$.

Conclusion: Consistent with previous literature, patients perceive Medicare reimbursement for RCR to be higher than what surgeons are actually reimbursed. As the United States health care system enters a bundled care environment, price transparency is increasingly important. This study indicates a need for patient education on how their health care costs are allocated.

Keywords: Medicare; shoulder surgery; survey study; arthroscopic rotator cuff repair; open rotator cuff repair

Over the past decade, changes to the health care system in the United States have been a consistent topic of political

\footnotetext{
*Address correspondence to Brendan R. Southam, MD, Department of Orthopaedic Surgery, University of Cincinnati Medical Center, PO Box 670212, Cincinnati, OH 45267-0212, USA (email: Brendan.Southam@uc

${ }^{\top}$ Department of Orthopaedic Surgery, University of Cincinnati Medical Center, Cincinnati, Ohio, USA.

One or more of the authors has declared the following potential conflict of interest or source of funding: B.R.S. has received research support from DePuy Synthes. B.M.G. has received educational support from Arthrex and hospitality payments from Smith \& Nephew. AOSSM checks author disclosures against the Open Payments Database (OPD). AOSSM has not conducted an independent investigation on the OPD and disclaims any liability or responsibility relating thereto.

Ethical approval for this study was obtained from the University of Cincinnati Institutional Review Board (IRB ID: 2016-5240).
} .edu).

The Orthopaedic Journal of Sports Medicine, 6(9), 2325967118795712 DOI: $10.1177 / 2325967118795712$

(c) The Author(s) 2018 debate. ${ }^{1}$ While the focus of much discussion is on private insurance costs, Medicare serves as the benchmark that private insurance companies use to set reimbursement schedules. $^{3,8,11,15}$ Medicare has continued to gradually reduce physician reimbursement, while practice operating costs and cost of living expenses for physicians continue to rise. ${ }^{5,9,13}$

Rotator cuff repair (RCR) is a relatively common orthopaedic procedure that is expected to be performed increasingly in the aging Medicare population as patients continue to remain active later in life. ${ }^{10}$ The amount that Medicare reimburses for many orthopaedic surgical procedures has declined substantially in recent years, with a $68 \%$ decrease in reimbursement for RCR since $1992 .{ }^{11}$ Meanwhile, studies in the arthroplasty, spine, and shoulder and elbow literature have shown that patients perceive Medicare reimbursement to surgeons to be much higher than current reimbursement schedules. $1,5,9,13$

The purpose of this study was to evaluate patient perceptions of Medicare reimbursement for various RCR

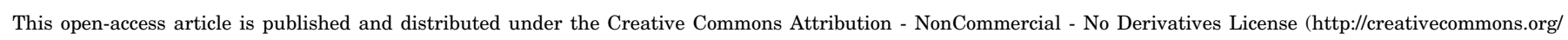

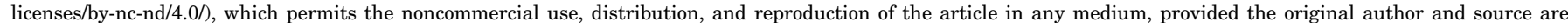

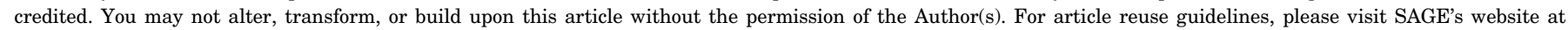
http://www.sagepub.com/journals-permissions. 
procedures. Based on the results of previous studies, we hypothesized that patients would overestimate surgeon reimbursement rates for these procedures. Additionally, we sought to evaluate how these perceptions of reimbursement varied between patients who had previously undergone shoulder surgery versus those presenting with new complaints of shoulder pain or new complaints of hip or knee pain. We hypothesized that patients with previous shoulder surgery would overestimate reimbursement to surgeons relative to other patients. Finally, previous studies have demonstrated that when presented with the actual reimbursement amounts, patients typically believe that surgeons should be paid more to perform these procedures. ${ }^{1,5,9,13}$ Thus, we also sought to evaluate whether patients felt this way regarding RCR procedures.

\section{METHODS}

Following institutional review board approval, 153 patients who presented to a single surgeon's orthopaedic sports medicine clinic between October 2016 and March 2017 were surveyed. Upon presentation for their regularly scheduled visit, patients' medical records were screened by a research fellow (B.R.S.) to determine whether inclusion criteria for the study were met. Inclusion criteria included patients presenting with a new complaint of hip or knee pain, those with a new complaint of shoulder pain, or those who had undergone shoulder surgery 1 or more years before their current visit. If these criteria were met, patients were approached by the research fellow and asked to complete a voluntary, confidential survey on patient perceptions of surgeon reimbursement while they were waiting to be seen by the surgeon. Those who chose to participate were given a paper survey, which they completed and returned to the research fellow or office staff to maintain anonymity with the treating surgeon.

Surveys were modeled after similar, previously conducted studies ${ }^{1,5,9,14}$ and were divided into 4 sections (Appendix). In the first section, basic demographic data were collected, including age, sex, race, insurance status, annual household income level, highest level of education, and history of previous orthopaedic surgeries.

In the second section of the survey, patients were asked to estimate how much they thought surgeons should be reimbursed for various RCR procedures, including arthroscopic repair of a simple tear, arthroscopic repair of a massive tear, open repair of an acute tear, and open repair of a chronic tear. Patients were also later asked how much surgeons should be reimbursed for other common surgical procedures, including laparoscopic cholecystectomy and mitral valve replacement. For each of these surgeries, patients were then asked in the next question how much they thought the actual Medicare reimbursement to surgeons was.

The third section provided patients with the actual state reimbursement data from Medicare for the previously described operations based on the following Current Procedural Terminology (CPT) codes: 29827, 23410, 23412, 47562 , and $33430 .{ }^{4}$ This section of the survey was on the pages that followed section 2 so as not to influence patient

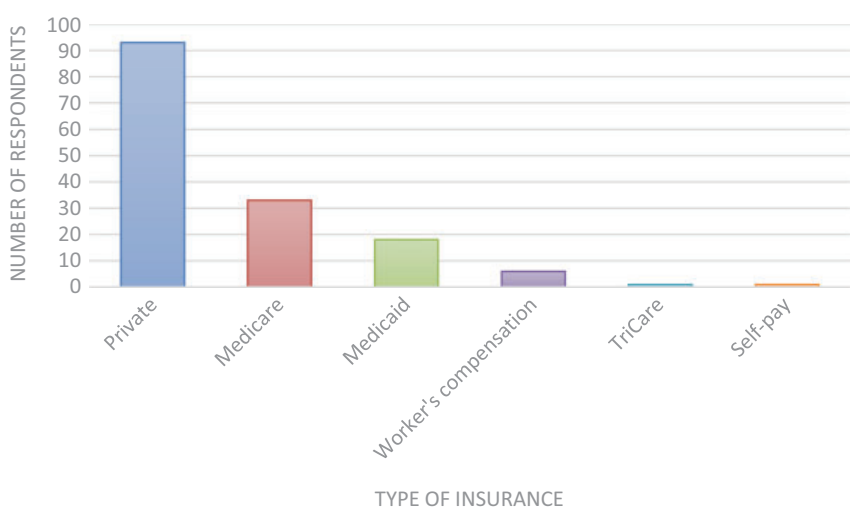

Figure 1. Insurance type of respondents.

responses regarding perceived reimbursement. Patients were asked whether they believed surgeons should be reimbursed more or less than the given Medicare reimbursement amount.

In section 4 , patients were asked to provide their opinion on whether surgeons are fairly reimbursed by Medicare and whether surgeons will continue to accept Medicare patients based on the reimbursement data. Finally, patients were asked if they were aware of the 90-day global period, in which a surgeon does not receive any additional payments from Medicare for office visits which take place up to 90 days after surgery.

All data were entered into Microsoft Excel for statistical analysis. Demographic data were analyzed by use of basic descriptive statistics. For section 2, which compared patients' estimates of surgeon reimbursement versus what they believed physicians should be reimbursed for various RCR surgeries, $t$ tests were conducted to compare these responses, and $P<.05$ was considered significant. Additional $t$ tests were conducted to compare actual state Medicare reimbursement amounts to these responses using the Real Statistics Resource Pack software (release 5.1) singlesample $t$ test. Additionally, a 1-way analysis of variance (ANOVA) was performed to compare responses between each group of patients (new hip or knee pain, new shoulder pain, and previous shoulder surgery) for each of the RCR surgeries. As well, $t$ tests were conducted to compare the responses between each of these groups. To control for outliers, the highest and lowest $5 \%$ of patient responses for each question were excluded prior to analysis.

\section{RESULTS}

The 153 patients surveyed had a mean age of 52.5 years (range, 18-85 years); 70 male patients (45.8\%) and 83 female patients $(54.2 \%)$ were included in the study. Most patients had either private insurance $(93 / 153,60.8 \%)$ or Medicare (33/153, 21.6\%) (Figure 1). The median patient income was $\$ 75,000-\$ 100,000$ (Figure 2). The breakdown for highest level of education is shown in Figure 3. Overall, 104 patients $(68.0 \%)$ had undergone previous orthopaedic surgery. 


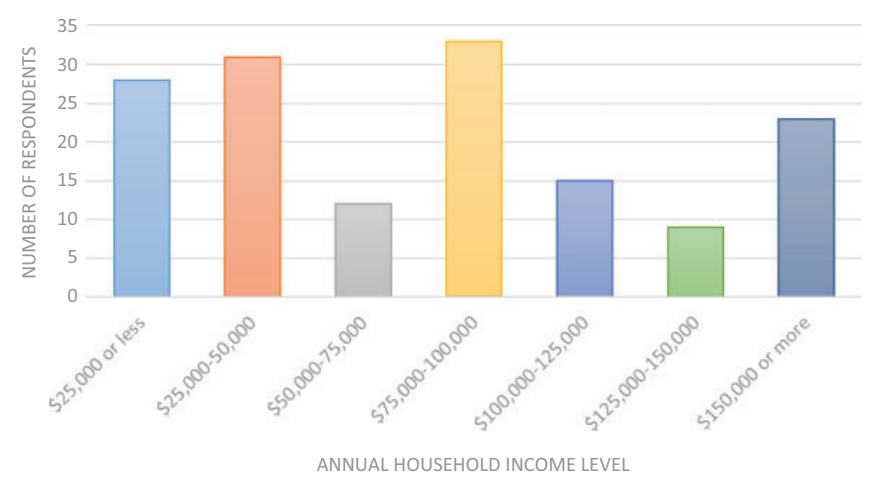

Figure 2. Annual household income of respondents.

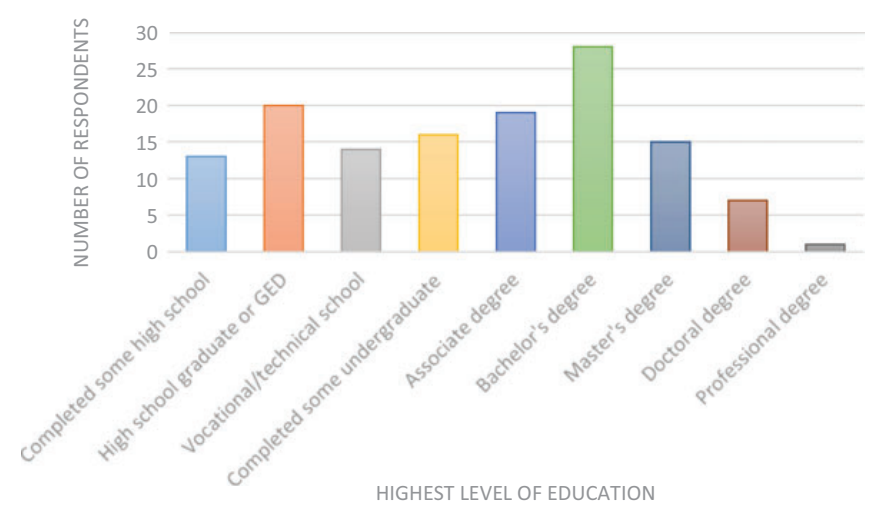

Figure 3. Highest level of education of respondents.

For arthroscopic repair of a rotator cuff tear, patients believed that surgeons should receive a mean reimbursement of US $\$ 5645$, which was significantly more than their estimate of what surgeons were actually reimbursed by Medicare $(\$ 3644, P=.001)$. Patients also believed that orthopaedic surgeons should be reimbursed more than their estimate of what surgeons were reimbursed for arthroscopic repair of a massive tear ( $\$ 8066$ vs $\$ 4694$, $P=.0001)$, open repair of an acute tear $(\$ 8428$ vs $\$ 4549$, $P=.00001)$, and open repair of a chronic tear (\$8902 vs $\$ 4639, P=.00001)$. Patients also indicated that general surgeons and cardiothoracic surgeons should be reimbursed significantly more than their estimate of what these surgeons were reimbursed for laparoscopic cholecystectomies ( $\$ 5789$ vs $\$ 3264, P=.00001)$ and for mitral valve replacements $(\$ 18,089$ vs $\$ 10,333, P=.00005)$, respectively. While patients believed that surgeons should be reimbursed more for an arthroscopic repair of a massive tear compared with a simple tear $(\$ 8066$ vs $\$ 5645, P=$ .004), no other significant differences were observed between the RCR procedures. When comparing the responses between the 3 patient groups (new hip/knee pain, new shoulder pain, and previous shoulder surgery), there were no significant differences regarding what the patients believed surgeons should be reimbursed versus their estimate of reimbursement, for any procedure (Figure 4).
When we compared the patients' estimated reimbursement and the amount they believed that surgeons should be reimbursed with the actual state Medicare reimbursement data, we found that patients significantly overestimated both of these values for all 6 surgeries (Table 1). All $P$ values were less than .001. Patient responses for estimated reimbursement versus what they believed surgeons should be reimbursed for each of the RCR procedures were evaluated according to the type of insurance the patient had (Table 2). Responses were also evaluated according to highest education level (Table 3 ) and annual household income level (Table 4). Comparing patients with private insurance versus those with Medicaid, Medicare, and workers' compensation, we noted no significant differences between groups with regard to how much these patients believed surgeons should be reimbursed for each of the procedures. Similarly, when comparing patients who had undergone previous orthopaedic surgery versus those with no history of orthopaedic surgery, we found no significant differences between groups for each procedure.

When given the actual Medicare reimbursement (MR) rates for arthroscopic repairs, $71 \%$ of patients believed reimbursement should be higher for simple tears (MR, \$1052) and $84 \%$ believed it should be higher for massive tears (MR, \$1052). For open repairs, 86\% of patients believed reimbursement should be higher for repair of acute tears (MR, \$816) and 88\% believed it should be higher for repair of chronic tears (MR, \$846). Sixty-eight percent of patients believed that surgeons were not fairly reimbursed, and $44 \%$ believed that surgeons would no longer continue to see Medicare patients based on current reimbursement. Seventyeight percent of patients who participated in this study were unaware of the global period prior to completing the survey.

\section{DISCUSSION}

Previous research has indicated that patients believe physicians are largely overpaid; however, more recent research suggests that patients think surgeons should be reimbursed 4 times current reimbursement rates. ${ }^{5,12}$ This study sought to evaluate patient perceptions of surgeon reimbursement for RCR procedures and how these were influenced by previous RCR versus patients presenting with new complaints. Additionally, patients were given actual reimbursement data for these procedures and asked to provide their opinion on whether surgeons should be reimbursed that amount for each procedure. Considering previous research, we hypothesized that patients would overestimate the actual amount that Medicare reimburses for each of the procedures described in the questionnaire. Consistent with the literature, patients in this study perceived Medicare reimbursement for RCR to be much higher than it actually is and believed that reimbursement should be much higher than it is currently. ${ }^{1,5,9,13}$

This effect was observed across all RCR procedures. Nagda et $\mathrm{al}^{9}$ demonstrated that patients estimate Medicare reimbursement for RCR surgery to be approximately 3 times the amount that orthopaedic surgeons are actually reimbursed ( $\$ 4692$ vs $\$ 1175$ ). Foran et $\mathrm{al}^{5}$ found that 


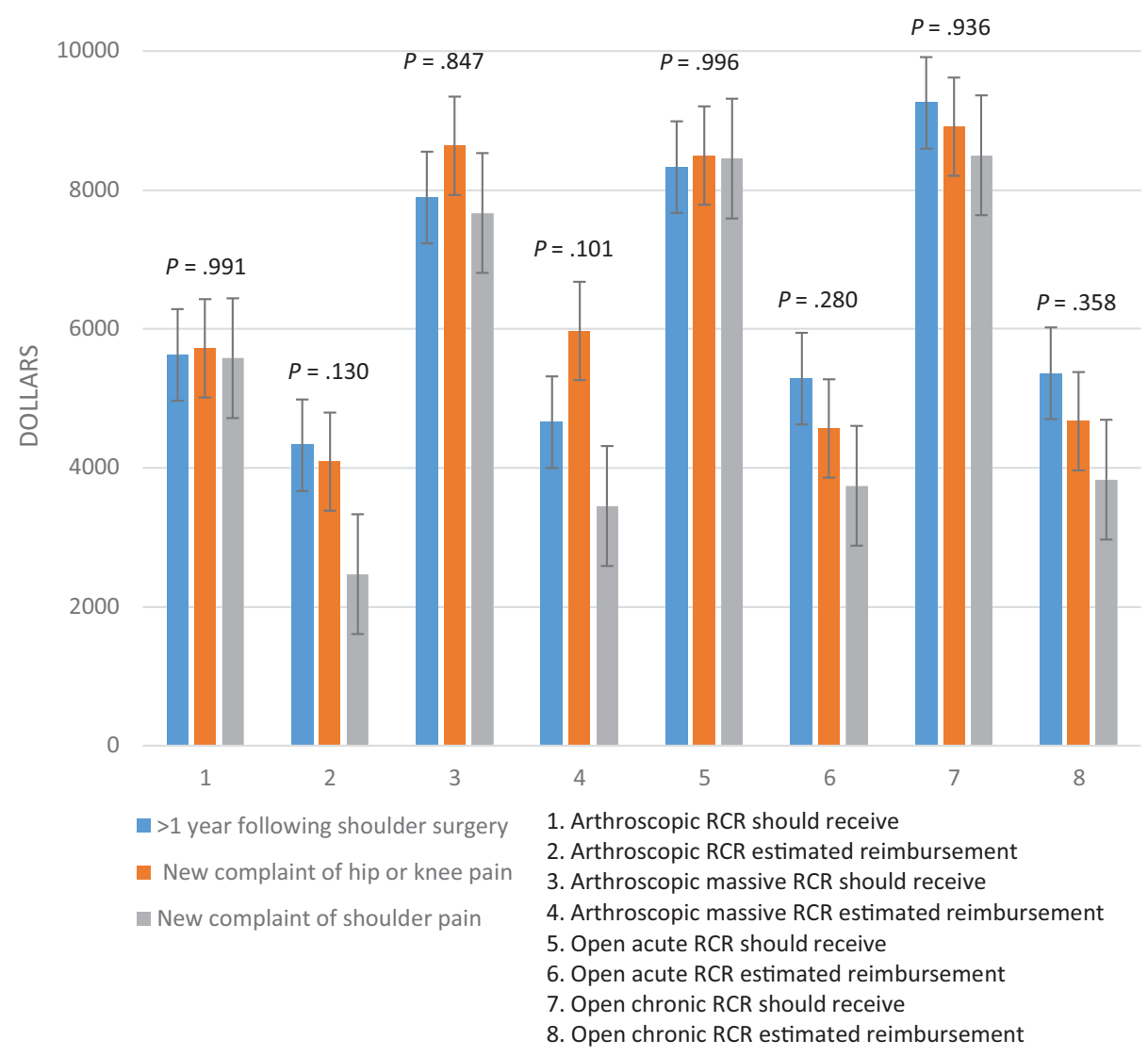

Figure 4. Analysis of variance (ANOVA) comparison of patient perceptions of reimbursement between groups. The ANOVA conducted found no significant difference in patient perceptions of reimbursement for each of the procedures between the 3 groups surveyed. However, $t$ tests performed between each of the groups revealed a significant difference between what group 1 and group 3 thought Medicare reimbursed surgeons for arthroscopic repair of simple tears (question 2, $P<.027$ ). RCR, rotator cuff repair.

TABLE 1

Patient Reimbursement Responses Versus Actual State Medicare Reimbursement ${ }^{a}$

Reimbursement Responses

Patient Response, Actual State Medicare mean \pm SEM Reimbursement $P$ Value $\quad 95 \% \mathrm{CI}$

1. Arthroscopic RCR should receive

$\begin{array}{rrrc}5645 \pm 442 & 1052.28 & 8.46 \mathrm{E}-19 & 4779-6511 \\ 3644 \pm 408 & 1052.28 & 2.97 \mathrm{E}-09 & 2845-4443 \\ 8066 \pm 708 & 1052.28 & 1.09 \mathrm{E}-17 & 6678-9453 \\ 4694 \pm 476 & 1052.28 & 3.6 \mathrm{E}-12 & 3760-5627 \\ 8428 \pm 768 & 816.22 & 1.08 \mathrm{E}-17 & 6922-9934 \\ 4549 \pm 396 & 816.22 & 1.67 \mathrm{E}-16 & 3773-5325 \\ 8902 \pm 844 & 846.97 & 8.47 \mathrm{E}-17 & 7248-10,555 \\ 4639 \pm 438 & 846.97 & 2.5 \mathrm{E}-14 & 3781-5498 \\ 5789 \pm 476 & 663.87 & 7.32 \mathrm{E}-20 & 4856-6722 \\ 3264 \pm 285 & 663.87 & 8.84 \mathrm{E}-16 & 2706-3821 \\ 18,089 \pm 1571 & 2857.12 & 4.7 \mathrm{E}-17 & 15,009-21,168 \\ 10,333 \pm 1018 & 2857.12 & 3.4 \mathrm{E}-11 & 8338-12,329\end{array}$

2. Arthroscopic RCR estimated reimbursement

3. Arthroscopic massive RCR should receive

4. Arthroscopic massive RCR estimated reimbursement

5. Open acute RCR should receive

6. Open acute RCR estimated reimbursement

7. Open chronic RCR should receive

8. Open chronic RCR estimated reimbursement

9. Laparoscopic cholecystectomy should receive

10. Laparoscopic cholecystectomy estimated reimbursement

11. Mitral valve replacement should receive

12. Mitral valve replacement estimated reimbursement

$10,333 \pm 1018$

${ }^{a}$ Values for "patient response," "actual state Medicare reimburesment," and 95\% CIs are in US $\$$. RCR, rotator cuff repair. 
TABLE 2

Patient Reimbursement Responses by Insurance Type ${ }^{a}$

\begin{tabular}{|c|c|c|c|c|c|c|c|c|c|c|c|c|c|c|c|c|}
\hline \multirow[b]{2}{*}{$\begin{array}{l}\text { Insurance } \\
\text { Status }\end{array}$} & \multicolumn{4}{|c|}{ Arthroscopic RCR } & \multicolumn{4}{|c|}{ Arthroscopic Massive RCR } & \multicolumn{4}{|c|}{ Open Acute RCR } & \multicolumn{4}{|c|}{ Open Chronic RCR } \\
\hline & $\begin{array}{l}\text { Should } \\
\text { Receive }\end{array}$ & ER & $P$ & $95 \% \mathrm{CI}$ & $\begin{array}{l}\text { Should } \\
\text { Receive }\end{array}$ & ER & $P$ & $95 \% \mathrm{CI}$ & $\begin{array}{l}\text { Should } \\
\text { Receive }\end{array}$ & ER & $P$ & $95 \% \mathrm{CI}$ & $\begin{array}{l}\text { Should } \\
\text { Receive }\end{array}$ & ER & $P$ & $95 \% \mathrm{CI}$ \\
\hline Private $(\mathrm{n}=93)$ & $5530 \pm 566$ & $3719 \pm 535$ & .021 & $4403-6657$ & $7471 \pm 774$ & $4146 \pm 487$ & .000389 & $5932-9010$ & $8461 \pm 1017$ & $4608 \pm 521$ & .000994 & $6439-10,485$ & $8996 \pm 1106$ & $4603 \pm 569$ & .000579 & $6796-11196$ \\
\hline Medicare $(\mathrm{n}=33)$ & $5117 \pm 977$ & $2780 \pm 556$ & .047 & $3116-7119$ & $8067 \pm 2034$ & $5743 \pm 1546$ & .394 & $3906-12,227$ & $7268 \pm 1371$ & $4483 \pm 837$ & .094 & $4455-10,081$ & $7696 \pm 1438$ & $4533 \pm 910$ & .072 & $4746-10,647$ \\
\hline Medicaid $(\mathrm{n}=18)$ & $5713 \pm 1199$ & $4392 \pm 1584$ & .512 & $3141-8286$ & $8921 \pm 1758$ & $5013 \pm 1056$ & .068 & $2750-7277$ & $10,125 \pm 2642$ & $4643 \pm 1175$ & .072 & $4493-15,757$ & $9536 \pm 3055$ & $5680 \pm 1426$ & .266 & $3023-16,048$ \\
\hline $\begin{array}{l}\text { Workers' compensation } \\
\quad(\mathrm{n}=6)\end{array}$ & $8200 \pm 2083$ & $4625 \pm 2211$ & .279 & $2416-13,984$ & $11,700 \pm 4908$ & $6500 \pm 2880$ & .395 & $0-25327$ & $7750 \pm 2529$ & $4000 \pm 913$ & .240 & $0-15,798$ & $12,250 \pm 4385$ & $3125 \pm 315$ & .129 & $0-26,205$ \\
\hline
\end{tabular}

${ }^{a}$ Values for "should receive," "estimated reimbursement" (ER), and 95\% CIs are in US\$. TriCare and self-pay were excluded due to only 1 respondent for each category. ER, Estimated Reimbursement; RCR, rotator cuff repair.

TABLE 3

Patient Reimbursement Responses by Highest Education Level ${ }^{a}$

\begin{tabular}{|c|c|c|c|c|c|c|c|c|c|c|c|c|c|c|c|c|}
\hline \multirow[b]{2}{*}{ Education Level } & \multicolumn{4}{|c|}{ Arthroscopic RCR } & \multicolumn{4}{|c|}{ Arthroscopic Massive RCR } & \multicolumn{4}{|c|}{ Open Acute RCR } & \multicolumn{4}{|c|}{ Open Chronic RCR } \\
\hline & $\begin{array}{l}\text { Should } \\
\text { Receive }\end{array}$ & $\mathrm{ER}$ & $P$ & $95 \% \mathrm{CI}$ & $\begin{array}{l}\text { Should } \\
\text { Receive }\end{array}$ & ER & $P$ & $95 \% \mathrm{CI}$ & $\begin{array}{l}\text { Should } \\
\text { Receive }\end{array}$ & ER & $P$ & $95 \% \mathrm{CI}$ & $\begin{array}{l}\text { Should } \\
\text { Receive }\end{array}$ & ER & $P$ & $95 \% \mathrm{CI}$ \\
\hline Completed some high school $(\mathrm{n}=13)$ & $3678 \pm 930$ & $2311 \pm 727$ & .265 & $1534-5821$ & $6880 \pm 2256$ & $4510 \pm 1484$ & .393 & $1777-11,983$ & $7430 \pm 2702$ & $3722 \pm 858$ & .218 & $1318-13,542$ & $5189 \pm 1375$ & $4400 \pm 959$ & .645 & $2019-8359$ \\
\hline $\begin{array}{l}\text { High school graduate or equivalent } \\
\text { (GED) }(\mathrm{n}=20)\end{array}$ & $6400 \pm 1524$ & $5633 \pm 1650$ & .735 & $3185-9615$ & $8485 \pm 1950$ & $6833 \pm 1799$ & .538 & $4352-12,618$ & $8912 \pm 2449$ & $6160 \pm 1452$ & .343 & $3720-14,103$ & $11,317 \pm 2768$ & $6875 \pm 1610$ & .178 & $5417-17,217$ \\
\hline $\begin{array}{l}\text { Vocational/technical school } \\
\qquad(\mathrm{n}=14)\end{array}$ & $6875 \pm 1264$ & $4945 \pm 2154$ & .451 & $4092-9658$ & $10,950 \pm 2608$ & $3468 \pm 528$ & .019 & $5050-16,850$ & $11,955 \pm 2979$ & $5614 \pm 1531$ & .078 & $5317-18,592$ & $14,346 \pm 3968$ & $5163 \pm 1584$ & .048 & $5702-22,991$ \\
\hline $\begin{array}{l}\text { Completed some undergraduate } \\
\text { coursework }(\mathrm{n}=16)\end{array}$ & $6657 \pm 1486$ & $2863 \pm 835$ & .034 & $3535-9781$ & $12,060 \pm 3395$ & $6274 \pm 2278$ & .166 & $4954-19,166$ & $11,250 \pm 3230$ & $3472 \pm 889$ & .030 & $4490-18,010$ & $11,100 \pm 3346$ & $3228 \pm 1053$ & .035 & $3974-10,883$ \\
\hline Associate's degree $(\mathrm{n}=19)$ & $5831 \pm 1377$ & $3020 \pm 703$ & .082 & $2896-8766$ & $6658 \pm 1377$ & $4238 \pm 890$ & .151 & $3753-9564$ & $7312 \pm 1778$ & $4103 \pm 1031$ & .131 & $3542-11,082$ & $6859 \pm 1621$ & $4044 \pm 981$ & .149 & $3422-10,296$ \\
\hline Bachelor's degree $(\mathrm{n}=28)$ & $4845 \pm 779$ & $2706 \pm 599$ & .033 & $3258-6433$ & $6167 \pm 811$ & $3167 \pm 494$ & .003 & $4519-7816$ & $7027 \pm 1157$ & $4079 \pm 792$ & .040 & $4677-9377$ & $7364 \pm 1262$ & $4203 \pm 921$ & .047 & $4799-9929$ \\
\hline Master's degree $(\mathrm{n}=15)$ & $5675 \pm 1084$ & $3828 \pm 788$ & .179 & $3364-7986$ & $8275 \pm 1398$ & $5188 \pm 1047$ & .088 & $5296-11,254$ & $7963 \pm 1399$ & $4988 \pm 1007$ & .096 & $4981-10,944$ & $8069 \pm 1560$ & $4885 \pm 1089$ & .106 & $4744-11,394$ \\
\hline
\end{tabular}
${ }^{a}$ Vair.

TABLE 4

Patient Reimbursement Responses by Annual Household Income Level ${ }^{a}$

\begin{tabular}{|c|c|c|c|c|c|c|c|c|c|c|c|c|c|c|c|c|}
\hline \multirow[b]{2}{*}{$\begin{array}{l}\text { Annual Household } \\
\text { Income }\end{array}$} & \multicolumn{4}{|c|}{ Arthroscopic RCR } & \multicolumn{4}{|c|}{ Arthroscopic Massive RCR } & \multicolumn{4}{|c|}{ Open Acute RCR } & \multicolumn{4}{|c|}{ Open Chronic RCR } \\
\hline & $\begin{array}{l}\text { Should } \\
\text { Receive }\end{array}$ & ER & $P$ & $95 \% \mathrm{CI}$ & $\begin{array}{l}\text { Should } \\
\text { Receive }\end{array}$ & ER & $P$ & $95 \% \mathrm{CI}$ & $\begin{array}{l}\text { Should } \\
\text { Receive }\end{array}$ & ER & $P$ & $95 \% \mathrm{CI}$ & $\begin{array}{l}\text { Should } \\
\text { Receive }\end{array}$ & ER & $P$ & $95 \% \mathrm{CI}$ \\
\hline$\leq 25,000(\mathrm{n}=28)$ & $6328 \pm 1046$ & $4136 \pm 1053$ & .146 & $4170-8486$ & $10,260 \pm 2273$ & $6278 \pm 1676$ & .166 & $5578-14,941$ & $8576 \pm 1369$ & $4410 \pm 673$ & .010 & $5758-11,395$ & $7984 \pm 1244$ & $4913 \pm 725$ & .039 & $5421-10,546$ \\
\hline $25,000-50,000(\mathrm{n}=31)$ & $5612 \pm 904$ & $4258 \pm 1139$ & .357 & $3750-7473$ & $8027 \pm 1348$ & $5866 \pm 1258$ & .247 & $5250-10,804$ & $10,544 \pm 2588$ & $5297 \pm 1137$ & .072 & $5224-15,865$ & $11,335 \pm 2910$ & $5287 \pm 1223$ & .064 & $5341-17,328$ \\
\hline $50,000-75,000(\mathrm{n}=12)$ & $6058 \pm 1769$ & $2429 \pm 926$ & .087 & 2164-9953 & $8545 \pm 2636$ & $3109 \pm 910$ & .074 & $2672-14,418$ & $10,227 \pm 3491$ & $3913 \pm 1488$ & .119 & $2449-18,006$ & $10,336 \pm 3630$ & $4179 \pm 1698$ & .146 & $2248-18,424$ \\
\hline $75,000-100,000(\mathrm{n}=33)$ & $5893 \pm 1049$ & $4698 \pm 1096$ & .435 & $3736-8049$ & $9230 \pm 1802$ & $5309 \pm 1061$ & .067 & $5534-12,927$ & $8026 \pm 1369$ & $5031 \pm 855$ & .070 & $5221-10,831$ & $9926 \pm 1771$ & $4798 \pm 870$ & .013 & $6299-13,553$ \\
\hline $100,000-125,000(\mathrm{n}=15)$ & $5731 \pm 1614$ & $2560 \pm 745$ & .092 & 2214-9247 & $5917 \pm 1277$ & $2829 \pm 760$ & .052 & $3105-8727$ & $7500 \pm 1580$ & $4846 \pm 1468$ & .232 & $3980-11,020$ & $7273 \pm 1212$ & $4504 \pm 1724$ & .202 & 4571-9974 \\
\hline $125,000-150,000(\mathrm{n}=9)$ & $5500 \pm 1232$ & $3469 \pm 1107$ & .245 & $2334-8666$ & $7014 \pm 2002$ & $4181 \pm 1179$ & .251 & $2115-11,914$ & $6313 \pm 1698$ & $3456 \pm 610$ & .149 & $2297-10,328$ & $7500 \pm 2411$ & $3994 \pm 1041$ & .213 & $1799-13,201$ \\
\hline$\geq 150,000(\mathrm{n}=23)$ & $4405 \pm 1074$ & $2636 \pm 838$ & .202 & $2157-6653$ & $5645 \pm 1045$ & $3168 \pm 657$ & .052 & $3478-7813$ & $6848 \pm 1658$ & $3929 \pm 1023$ & .143 & $3390-10,305$ & $6768 \pm 1775$ & $4130 \pm 1175$ & .223 & $3077-10,459$ \\
\hline
\end{tabular}

${ }^{a}$ Values for "annual household income," "should receive," "estimated reimbursement" (ER), and 95\% CIs are in US\$. RCR, rotator cuff repair.

patients overestimate the reimbursement for total hip arthroplasty and total knee arthroplasty by a factor of approximately 6 times for each procedure. Despite patient perceptions, Medicare reimbursements to orthopaedic surgeons continue to decline..$^{2,6,7,11}$

When patients in the current study were provided with the actual reimbursement data for each of the RCR procedures, between $71 \%$ and $88 \%$ of patients believed that orthopaedic surgeons should be reimbursed more than the actual Medicare reimbursement depending on the procedure. In contrast, only approximately $4 \%$ of patients thought that surgeons were overreimbursed for any RCR procedure. These results are similar to the results of Nagda et al, ${ }^{9}$ who found that $75.7 \%$ of patients believed that reimbursement for RCR was lower than it should be, while $11.8 \%$ believed that reimbursement was fair and $2.5 \%$ believed it was more than it should be. However, these findings are in contrast to previous work by Ross and Lauritsen ${ }^{12}$ from 1985, which indicated that approximately $70 \%$ of the general public believed that physicians were paid too much, preceded only by movie stars, professional athletes, and top executives. As previous authors have noted, these differences may reflect a changing public perception of physician reimbursement that has taken place over the past 30 
years. ${ }^{5,9}$ Additionally, it is possible that patients believe that subspecialized surgeons should receive increased reimbursement commensurate with their increased level of training. ${ }^{9}$ However, it is not possible to draw these conclusions from the present study.

A secondary goal of this study was to identify whether any differences existed in perceptions about surgeon reimbursement between each of the groups surveyed: patients with a new complaint of hip or knee pain, those with a new complaint of shoulder pain, and those who had undergone shoulder surgery 1 or more years before their current visit. The single-factor ANOVA that was performed revealed no significant differences for either the estimated Medicare reimbursement or the reimbursement amount that patients believed surgeons should receive between the 3 groups. The $t$ tests performed between each of the groups revealed a significant difference in the amount that patients with a previous shoulder surgery versus those with a new complaint of shoulder pain thought Medicare reimbursed surgeons for arthroscopic repair of simple tears ( $\$ 4326$ vs $\$ 2469, P=.027)$. Although not significant, a similar trend was observed between these 2 groups for the amount that they believed Medicare reimbursed surgeons for each of the RCR procedures. This difference may be attributable to the perceived value that patients with previous shoulder surgery placed on the procedure. Alternatively, this difference may have been a result of the fact that patients who had undergone shoulder surgery were aware of their overall previous medical expenses and therefore used that amount as the frame of reference upon which they estimated Medicare reimbursement, causing them to estimate a higher amount.

In this study, patients appeared to place a higher value on the amount they believed that cardiothoracic surgeons should be reimbursed for mitral valve replacement relative to the amount they believed orthopaedic surgeons should be reimbursed for RCR. This finding is consistent with previous studies reporting that patients believe surgeons should be reimbursed more for coronary artery bypass graft surgery relative to both total shoulder arthroplasty and RCR as well as total hip arthroplasty and total knee arthroplasty. ${ }^{5,9}$ However, these studies also found that patients placed a lower value on appendectomy relative to those aforementioned procedures, indicating that they have some understanding of the relative complexity of these procedures. In contrast, our patients placed a similar value on laparoscopic cholecystectomy relative to arthroscopic RCR of a simple tear, which may indicate a belief that these procedures require a relatively similar level of technical skill and expertise. In this study, patients also believed that arthroscopic RCR of a massive tear should receive a significantly higher reimbursement than arthroscopic RCR for a simple tear, indicating an appreciation for the increased complexity associated with the repair of a larger tear.

Previous survey studies have reported that patients had independently expressed their concern over surgeons continuing to see Medicare patients in light of current reimbursements. ${ }^{1,5}$ Therefore, we sought to quantitatively measure the number of patients we surveyed who felt this way. We found that nearly half our population did not think surgeons would continue to accept Medicare based on current reimbursement, which they believed was too low. Additionally, several patients who had Medicare insurance indicated on their survey that they hoped their surgeon would continue to accept Medicare reimbursement and therefore disagreed with the question based on those grounds. These findings suggest that patients are growing concerned over whether their surgeon will continue to take their insurance. A previous study demonstrated that patients have a poor understanding of the global period, with nearly $75 \%$ of patients assuming that orthopaedic spine surgeons are reimbursed for all postoperative appointments that occur within the first 3 months after surgery. ${ }^{14}$ Given that this is an important concept in understanding physician reimbursement, we also decided to assess patient understanding of the global period in our survey population and found that nearly $80 \%$ of patients were unaware of the global period. Interestingly, this did not appear to be influenced by highest level of education, annual household income level, or history of previous orthopaedic surgery.

\section{Limitations}

Our study has several limitations that should be noted. First, we had a limited number of respondents $(\mathrm{N}=153$ patients) from a geographically distinct area in southwest Ohio, which is likely not representative of the general United States population. Second, approximately $30 \%$ of patients who met inclusion criteria chose not to participate in the study due to their own perceived lack of knowledge about surgeon reimbursement or a general lack of interest in participating. Thus, the population who chose to participate in the study may have biased the results. Prior to completing the survey, patients were reassured that the results of the survey were confidential. However, since the survey was administered in the surgeon's office prior to the patients' scheduled clinic visit, some patients might have perceived that their responses would influence the subsequent care they received, which may have affected their responses. Third, the format of the survey may have influenced responses, given that the survey asked patients what a surgeon should be reimbursed and then immediately asked for an estimate of what Medicare actually reimburses. Patients may have assumed that actual reimbursement was less than what they believed reimbursement should be and may have answered the questions based on that assumption.

\section{CONCLUSION}

The results of this survey indicate that patients believe surgeon reimbursement should be much higher than actual current Medicare reimbursement rates. This effect was observed across all RCR procedures irrespective of insurance, education level, or median household income. As the United States health care system enters a bundled care environment, price transparency is increasingly important, particularly in the elective surgery setting. This study indicates an increasing need for patient education on how health care costs are allocated. 


\section{REFERENCES}

1. Badlani N, Foran JR, Phillips FM, et al. Patient perceptions of physician reimbursement for spine surgery. Spine. 2013;38(15):1288-1293.

2. Bozic KJ, Cramer B, Albert TJ. Medicare and the orthopaedic surgeon: challenges in providing, financing, and accessing musculoskeletal care for the elderly. J Bone Joint Surg Am. 2010;92(6):1568-1574.

3. Clemens J, Gottlieb JD. In the shadow of a giant: Medicare's influence on private physician payments. $J$ Polit Econ. 2017;125(1):1-39.

4. CPT/Medicare Payment Search. https://apps.ama-assn.org/ CptSearch/user/search/cptSearch.do. Accessed November 15, 2017.

5. Foran JRH, Sheth NP, Ward SR, et al. Patient perception of physician reimbursement in elective total hip and knee arthroplasty. $J$ Arthroplasty. 2012;27(5):703-709.

6. Hariri S, Bozic KJ, Lavernia C, Prestipino A, Rubash HE. Medicare physician reimbursement: past, present, and future. J Bone Joint Surg Am. 2007;89(11):2536-2546.

7. Iglehart JK. Medicare's declining payments to physicians. $N$ Engl $J$ Med. 2002;346(24):1924-1930.

8. Krause TM, Ukhanova M, Revere FL. Private carriers' physician payment rates compared with Medicare and Medicaid. Tex Med. 2016; 112(6):e1.
9. Nagda S, Wiesel B, Abboud J, et al. Patient perception of physician reimbursement in elective shoulder surgery. J Shoulder Elbow Surg. 2015;24(1):106-110.

10. Narvy SJ, Didinger TC, Lehoang D, et al. Direct cost analysis of outpatient arthroscopic rotator cuff repair in Medicare and nonMedicare populations. Orthop J Sports Med. 2016;4(10): 2325967116668829.

11. Nordt J, Connair M, Gregorian J. As Medicare costs rise, reimbursements drop. AAOS Now. https://www.aaos.org/aaosnow/2012/dec/ cover/cover1/. Published December 2012. Accessed November 14, 2017.

12. Ross CE, Lauritsen J. Public opinion about doctors' pay. Am J Public Health. 1985;75(6):668-670.

13. Tucker JA, Scott CC, Thomas CS, O'Connor MI. Patient perception of Medicare reimbursement to orthopedic surgeons for THA and TKA. J Arthroplasty. 2013;28(suppl 8):144-147.

14. Welton KL, Gomberawalla MM, Gagnier JJ, Fischgrund JS, Graziano GP, Patel RD. Patient impressions of reimbursement for orthopedic spine surgeons. Spine J. 2015;15(11):2404-2409.

15. Woerheide J, Lake T, Rich EC. The role of government in physician reimbursement. Am J Med Sci. 2016;351(1):52-58.

\section{APPENDIX}

\section{Surgery Reimbursement Survey}

Please complete the following questions before beginning the survey.

Name:

Age:

Race:

White

$\square$ African American or Black

Hispanic or Latino

$\square$ Native American or American Indian

Asian

Pacific Islander

$\square$ Other (please specify):

Sex (check one): $\mathrm{M} \square \mathrm{F}$

Insurance provider:

Annual household income:
$\$ 25,000$ or less
$\$ 25,000-\$ 50,000$
$\square 50,000-\$ 75,000$
$\$ 75,000-\$ 100,000$
$\$ 100,000-\$ 125,000$
$\$ 125,000-\$ 150,000$
$\square 150,000$ or more 
Highest level of education:

Completed some high school

High school graduate or equivalent (GED)

Vocational/technical school

Completed some undergraduate coursework

Associate's degree

Bachelor's degree

Master's degree

Doctoral degree

Professional degree (MD, JD, etc)

What previous orthopaedic surgeries have you had?

Please answer the following questions. These questions refer to the amount of money the surgeon receives to perform the operation, the hospital care the surgeon provides to you after your operation, and all appointments you have with the surgeon that take place in the first 90 days following surgery. This does not include the cost of operating room fees, anesthesia care, preoperative testing, or hospital fees.

You must provide a dollar amount for each question below.

1. Arthroscopic repair of a rotator cuff tear involves using a small camera and surgical instruments placed into the shoulder joint to repair 1 of 4 muscles that stabilize the shoulder joint. How much do you think an orthopaedic surgeon should receive to perform an arthroscopic repair of a rotator cuff tear?

$\$$

2. How much do you think Medicare actually pays an orthopaedic surgeon to perform an arthroscopic repair of a rotator cuff tear and any office visits up to 90 days after surgery?

$\$$

3. Arthroscopic repair of a massive rotator cuff tear involves using a small camera and surgical instruments placed into the shoulder joint to repair 2 or 3 of the 4 muscles that stabilize the shoulder joint. How much do you think an orthopaedic surgeon should receive to perform an arthroscopic repair of a rotator cuff tear?

$\$$

4. How much do you think Medicare actually pays an orthopaedic surgeon to perform an arthroscopic repair of a massive rotator cuff tear and any office visits up to 90 days after surgery?

$\$$

5. Open repair of an acute rotator cuff tear involves making a traditional incision over the shoulder to repair the muscles that stabilize the shoulder joint. Acute tears occur as a result of an injury to the shoulder, typically a sports-related injury or a fall. How much do you think an orthopaedic surgeon should receive to perform an open repair of an acute rotator cuff tear?

$\$$

6. How much do you think Medicare actually pays an orthopaedic surgeon to perform an open repair of an acute rotator cuff tear and any office visits up to 90 days after surgery?

$\$$

7. Open repair of a chronic rotator cuff tear involves making a traditional incision over the shoulder to repair the muscles that stabilize the shoulder joint. Chronic tears are tears that occur slowly over time as a result of repetitive use and impingement. How much do you think an orthopaedic surgeon should receive to perform an open repair of a chronic rotator cuff tear?

$\$$ 
8. How much do you think Medicare actually pays an orthopaedic surgeon to perform an open repair of a chronic rotator cuff tear and any office visits up to 90 days after surgery?

$\$$

9. Laparoscopic cholecystectomy refers to a surgery performed by a general surgeon in which a small camera is placed into the abdomen and surgical instruments are used to remove the gallbladder. How much do you think a general surgeon should receive to perform a laparoscopic cholecystectomy?

$\$$

10. How much do you think Medicare actually pays a general surgeon to perform a laparoscopic cholecystectomy and any office visits up to 90 days after surgery?

$\$$

11. Mitral valve replacement is open heart surgery in which there is a problem with a valve in the heart, requiring the valve to be replaced. To do this, the heart must be placed on bypass and an incision is made in the left side of the heart and later repaired after the valve has been replaced. How much do you think a cardiothoracic (heart) surgeon should receive to perform a mitral valve replacement?

$\$$

12. How much do you think Medicare actually pays a cardiothoracic (heart) surgeon to perform a mitral valve replacement and any office visits up to 90 days after surgery?

$\$$

For these 6 surgeries, please rank from highest to lowest which surgery you think a surgeon should receive the highest reimbursement for. Number 1 should indicate the highest reimbursement and 6 should indicate the lowest reimbursement.

Arthroscopic repair of a rotator cuff tear

Arthroscopic repair of a massive rotator cuff tear

Open repair of an acute rotator cuff tear

Open repair of a chronic rotator cuff tear

Laparoscopic cholecystectomy

Mitral valve replacement 
Provided below are the actual Medicare reimbursements surgeons in the state of Ohio receive for each of these surgeries. Please indicate for each surgery whether you believe that surgeons should be reimbursed much lower, slightly lower, about that much, slightly higher, or much higher for each of these surgeries and any office visits in the 90 days after surgery.

1. Arthroscopic repair of a rotator cuff tear- $\$ 1052.28$

I think orthopaedic surgeons should be reimbursed

$\square$ Much lower

$\square$ Slightly lower

$\square$ About that much

$\square$ Slightly higher

$\square$ Much higher

2. Arthroscopic repair of a massive rotator cuff repair- $\$ 1052.28$

I think orthopaedic surgeons should be reimbursed

$\square$ Much lower

$\square$ Slightly lower

About that much

$\square$ Slightly higher

$\square$ Much higher

3. Open repair of an acute rotator cuff tear- $\$ 816.22$

I think orthopaedic surgeons should be reimbursed

$\square$ Much lower

$\square$ Slightly lower

$\square$ About that much

$\square$ Slightly higher

$\square$ Much higher

4. Open repair of a chronic rotator cuff tear- $\$ 846.97$

I think orthopaedic surgeons should be reimbursed

Much lower

$\square$ Slightly lower

$\square$ About that much

$\square$ Slightly higher

$\square$ Much higher

5. Laparoscopic cholecystectomy-\$663.87

I think general surgeons should be reimbursed

Much lower

$\square$ Slightly lower

$\square$ About that much

$\square$ Slightly higher

$\square$ Much higher

6. Mitral valve replacement- $\$ 2857.12$

I think cardiothoracic (heart) surgeons should be reimbursed

Much lower

Slightly lower 
About that much

Slightly higher

Much higher

Please answer the following questions.

1. Based on these reimbursements, I think surgeons will continue to see Medicare patients and accept Medicare.

$\square$ Strongly disagree

$\square$ Slightly disagree

$\square$ Neutral

$\square$ Slightly agree

Strongly agree

2. I think surgeons are reimbursed fairly by Medicare for surgeries and office visits up to 90 days after surgery.

Strongly disagree

Slightly disagree

$\square$ Neutral

$\square$ Slightly agree

$\square$ Strongly agree

Circle your answer below.

3. (Yes) / (No) Before taking this survey, I knew there was a global period after a surgery in which a surgeon does not receive any additional payments for office visits which take place up to 90 days after surgery.

Thank you for participating in our survey. Please return this survey to the researcher or office staff who gave it to you before leaving your appointment. 